\title{
Urinary [TIMP-2]*[IGFBP7] for early prediction of acute kidney injury after coronary artery bypass surgery
}

Kevin Pilarczyk*, Michaela Edayadiyil-Dudasova, Daniel Wendt, Ender Demircioglu, Jaroslav Benedik, Daniel Sebastian Dohle, Heinz Jakob and Fabian Dusse

\begin{abstract}
Background: Acute kidney injury (AKI) is a common complication after cardiac surgery. Currently, prediction of AKI with classical tools remains uncertain. Therefore, it was the aim of the present study to evaluate two new urinary biomarkers-insulin-like growth factor-binding protein 7 (IGFBP7) and tissue inhibitor of metalloproteinases-2 (TIMP-2) in patients after coronary artery bypass surgery (CABG).
\end{abstract}

Methods: In a prospective cohort study, 60 consecutive patients undergoing isolated on-pump CABG were enrolled. Urine samples collected every $12 \mathrm{~h}$ in the postoperative course were analyzed for the product of TIMP-2 and IGFBP7. Urinary output, serum creatinine and estimated glomerular filtration rate (eGFR) were recorded simultaneously. Primary clinical endpoint was the development of AKI stage 2 or 3 according to the classification of the KDIGO within $48 \mathrm{~h}$ after surgery.

Results: 48 male and 12 female patients with a mean age of $69.61 \pm 8.4$ years were included. 19 patients developed an AKI (31.6\%), six patients met the endpoint with AKI 2 or $3(10 \%)$. Urinary [TIMP-2]*[IGFBP7] increased significantly as early as $4 \mathrm{~h}$ after CABG in patients with AKI 2/3 (1.83 $\pm 2.15 \mathrm{vs} .0 .23 \pm 0.45, p<0.05)$ whereas serum creatinine did not increase until $48 \mathrm{~h}$ after surgery. The diagnostic accuracy of [TIMP 2]*[IGFBP7] on day one after surgery for the prediction of AKI $2 / 3$ was significantly better (sensitivity 0.89 , specificity 0.81 , AUC $0.817,95 \% \mathrm{Cl} 0.622-1.0 \mathrm{SE}$ $0.099, p=0.022$, cut-off 0.817 ) than for serum creatinine (AUC 0.359 , sensitivity 0.50 , specificity of 0.52 , cut-off value $1.17 \mathrm{mg} / \mathrm{dl})$ and eGFR.

Conclusion: Urinary [TIMP-2]*[IGFBP7] represents a sensitive and specific biomarker to predict moderate to severe $A K I$ very early after $C A B G$. Analyses from our ongoing larger study are necessary to confirm these findings and probably increase sensitivity and specificity.

Keywords: Acute kidney injury, CABG, Coronary artery bypass surgery, Cardiac surgery, Biomarker, Insulin-like growth factor-binding protein 7, IGFBP7, Tissue inhibitor of metalloproteinases-2, TIMP-2

\section{Background}

Acute kidney injury (AKI) is a common and serious complication after coronary artery bypass grafting (CABG). According to current definitions, AKI occurs in up to $40 \%$ of all patients undergoing cardiac surgery [1]. AKI

\footnotetext{
*Correspondence: kevin.pilarczyk@imland.de

Department of Thoracic and Cardiovascular Surgery, West German Heart and Vascular Center Essen, University Hospital Essen, Hufelandstr. 55, 45122 Essen, Germany
}

requiring renal replacement therapy has an incidence of approximately $1-5 \%$ [1]. The development of a postoperative AKI is associated with a more complicated clinical course and with an increased mortality of 15-30\%. Moreover, even slight changes of renal function are considered as an independent predictor of 30-day mortality [2]. Full recovery of renal function is only observed in $50 \%$ of surviving patients $[3,4]$. Thus, due to its significance, the term cardiac surgery-associated acute kidney injury (CSA AKI) was established. Risk assessment for 
AKI is recommended by clinical practice guidelines but remains imprecise mainly due to very limited sensitivity and specificity of early diagnostic tests available for AKI. Although serum creatinine is known to be an inadequate and delayed marker of acute changes in renal function, it is currently accepted as "gold standard" to diagnose AKI due to the lack of other reliable biomarkers. Obviously, there is a clear need for sensitive and specific biomarkers allowing early identification of patients with high risk for AKI to initiate preventive or therapeutic interventions [5-7].

Tissue inhibitor of metalloproteinases-2 (TIMP-2) and insulin-like growth factor binding protein 7 (IFGBP7) have recently been suggested as promising tools for the early detection of AKI in critically ill patients [8]. Both proteins are inducers of the G1 cell cycle arrest, considered as a key mechanism of AKI. In the Sapphire study enrolling 744 critically ill medical and surgical subjects with a moderate-severe AKI occurring in $14 \%$ of patients, the combination of TIMP-2 and IGFBP7 was significantly superior to all other existing markers of AKI with an AUC of 0.80 and also better than TIMP-2 (AUC 0.76) and IGFBP7 (AUC 0.79) alone [9]. Others could confirm these findings showing that urinary [TIMP-2]*[IGFBP7] greater than 0.3 $(\mathrm{ng} / \mathrm{ml})^{2} / 1000$ is able to identify patients at risk for imminent AKI [10]. In addition, urinary [TIMP-2]"[IGFBP7] is able to predict AKI and renal recovery early after cardiac surgery in a subgroup of patients with a high risk for the development of AKI defined by a high Cleveland Foundation Score [11]. Therefore, it was the aim of the present study to analyze the postoperative course of [TIMP 2]"[IGFBP7] to evaluate a new diagnostic approach for early detection of AKI in patients after isolated CABG.

\section{Methods}

\section{Patients}

The present study was approved by the Institutional Ethic Review Board and informed consent from the patient or the patient's next of kin was obtained. Sixty consecutive patients (minimum age: 18 years) scheduled for elective on-pump CABG due to severe coronary artery disease between January 2014 and October 2014 were consecutively recruited during their pre-admission attendance to participate in the study. We used the Standards for Reporting of Diagnostic Accuracy (STARD) statement for planning and conducting the study and preparing the manuscript [12].

\section{Surgical procedure}

Surgical revascularization was performed in all patients by using hypothermic cardiopulmonary bypass with cardioplegic arrest and median sternotomy as described previously [13]. Briefly, cannulation of the ascending aorta and two-stage venous cannulation was performed and standard nonpulsatile cardiopulmonary bypass (CPB) technique with a membrane oxygenator was initiated. During $\mathrm{CPB}$, moderate hemodilution with a hematocrit between 20 and $25 \%$ using mild systemic hypothermia $\left(32{ }^{\circ} \mathrm{C}\right)$ was maintained. Myocardial protection was performed using anterograde cold crystalloid Bretschneider solution (Custodiol, Köhler Chemie GmbH, Bensheim, Germany) for cardioplegic arrest with additional topical cooling and single aortic crossclamping for all distal anastomoses.

\section{Biomarker measurements}

Urine and blood samples for biomarker analysis were obtained $4 \mathrm{~h}$ after surgery and then every $12 \mathrm{~h}$ until discharge from ICU/IMC or for a maximum of 4 days, respectively. TIMP-2 and IGFBP7 in the urine were measured with the commercially available and FDAapproved NephroCheck ${ }^{\mathrm{TM}}$ Test (Astute Medical, San Diego, CA, USA) - a point-of-care test kit developed to measure and calculate the product of [TIMP-2] and [IGFBP7] concentration in the urine. Physicians in charge were blinded for the cell cycle arrest biomarker levels as well as laboratory investigators were blinded to clinical outcomes. Glomerular filtration rate was calculated with the Cockcroft-Gault formula (estimated Glomerular filtration rate $=\mathrm{eGFR}$ ).

\section{Definition of endpoint and outcomes}

AKI stage was determined daily on the basis of diuresis rate and serum creatinine concentration according to the Kidney Disease: Improving Global Outcomes classification (KDIGO) as follows [14]:

AKI 1 increase of serum creatinine by $\geq 0.3 \mathrm{mg} / \mathrm{dl}$ $(\geq 26.4 \mu \mathrm{mol} / \mathrm{L})$ or increase to $\geq 150-200 \%$ from baseline or urine output $<0.5 \mathrm{ml} / \mathrm{kg} / \mathrm{h}$ for $>6 \mathrm{~h}$;

AKI 2 increase of serum creatinine to $>200-300 \%$ from baseline and/or urine output $<0.5 \mathrm{ml} / \mathrm{kg} / \mathrm{h}$ for $>12 \mathrm{~h}$;

AKI 3 increase of serum creatinine to $>300 \%$ from baseline or serum creatinine $\geq 4.0 \mathrm{mg} / \mathrm{dl}$ $(\geq 354 \mu \mathrm{mol} / \mathrm{L})$ after a rise of at least $44 \mu \mathrm{mol} / \mathrm{L}$ or treatment with renal replacement therapy and/or urine output $<0.3 \mathrm{ml} / \mathrm{kg} / \mathrm{h}$ for $>24 \mathrm{~h}$ or anuria for $12 \mathrm{~h}$.

The primary endpoint was the new occurrence of acute kidney injury stage 2 or 3 within $48 \mathrm{~h}$ after surgery. This observation period was chosen because prior studies have shown that AKI occurs within the first 24-72 h after CABG in the majority of cases.

Sepsis and septic shock was defined according to the definition issued by the Surviving Sepsis Campaign [15]. 
Shock was distinguished as cardiogenic shock (low cardiac output syndrome) or septic shock. Low cardiac output syndrome (LCOS) was defined as the need for an intra-aortic balloon pump (IABP) in the operating room (to be weaned from cardiopulmonary bypass) or in the intensive care unit because of hemodynamic compromise or the need for inotropic medication (epinephrine $>0.25 \mu \mathrm{g} / \mathrm{kg} \mathrm{BW} / \mathrm{min}$ or milrinone $>1.5 \mathrm{mg} / \mathrm{h}$ ) to maintain systolic blood pressure greater than $90 \mathrm{mmHg}$ and cardiac output index greater than $2.2 \mathrm{l} / \mathrm{min} / \mathrm{m}^{2}$ for at least $30 \mathrm{~min}$ in the intensive care unit, after optimizing preload and afterload, correction of serum electrolyte, and blood gas abnormalities.

\section{Sample size calculation}

The aim of the present study was to proof the hypothesis that mean urine [TIMP-2]*[IGFBP7] levels in patients with AKI differ significantly to patients without AKI within the first $24 \mathrm{~h}$ after surgery.

Therefore, a one-tailed power analysis based on the available published data on [TIMP-2]*[IGFBP7] in the adult cardiothoracic population was performed to calculate the sample size. We aimed to detect a difference of one unit in [TIMP-2]"[IGFBP7] levels with a standard deviation of 0.8 units [10]. Expected incidence of AKI 2-3 was $10 \%$. With a given probability of type I error $(\alpha)$ of 0.05 , and a power $(1-\beta)$ of 0.9 , sample size calculation revealed a required minimum size of 60 patients at total.

\section{Statistical analysis}

Statistical analyses were performed with SPSS Statistics 19 (IBM, Chicago, IL). Continuous data were expressed as mean $\pm \mathrm{SD}$; categorical data were expressed as percentage. Comparisons between two groups were carried out using unpaired Student's $t$ test for normally or the Mann-Whitney Rank Sum Test for non-normally distributed data. Multiple groups were compared with ANOVA. Statistical significance was assumed for a $p$ value $<0.05$. To measure the sensitivity and specificity of urinary [TIMP-2]*[IGFBP7] at different cut-off values, a conventional receiver operating characteristic (ROC) curve was generated. The optimal cut-off level was defined by the largest sum of sensitivity and specificity. Comparison of ROC curves was performed with the DeLong-Test.

\section{Results}

\section{Patients' characteristics}

60 patients undergoing isolated first-time CABG were included in this study (see Fig. 1). AKI of any stage within

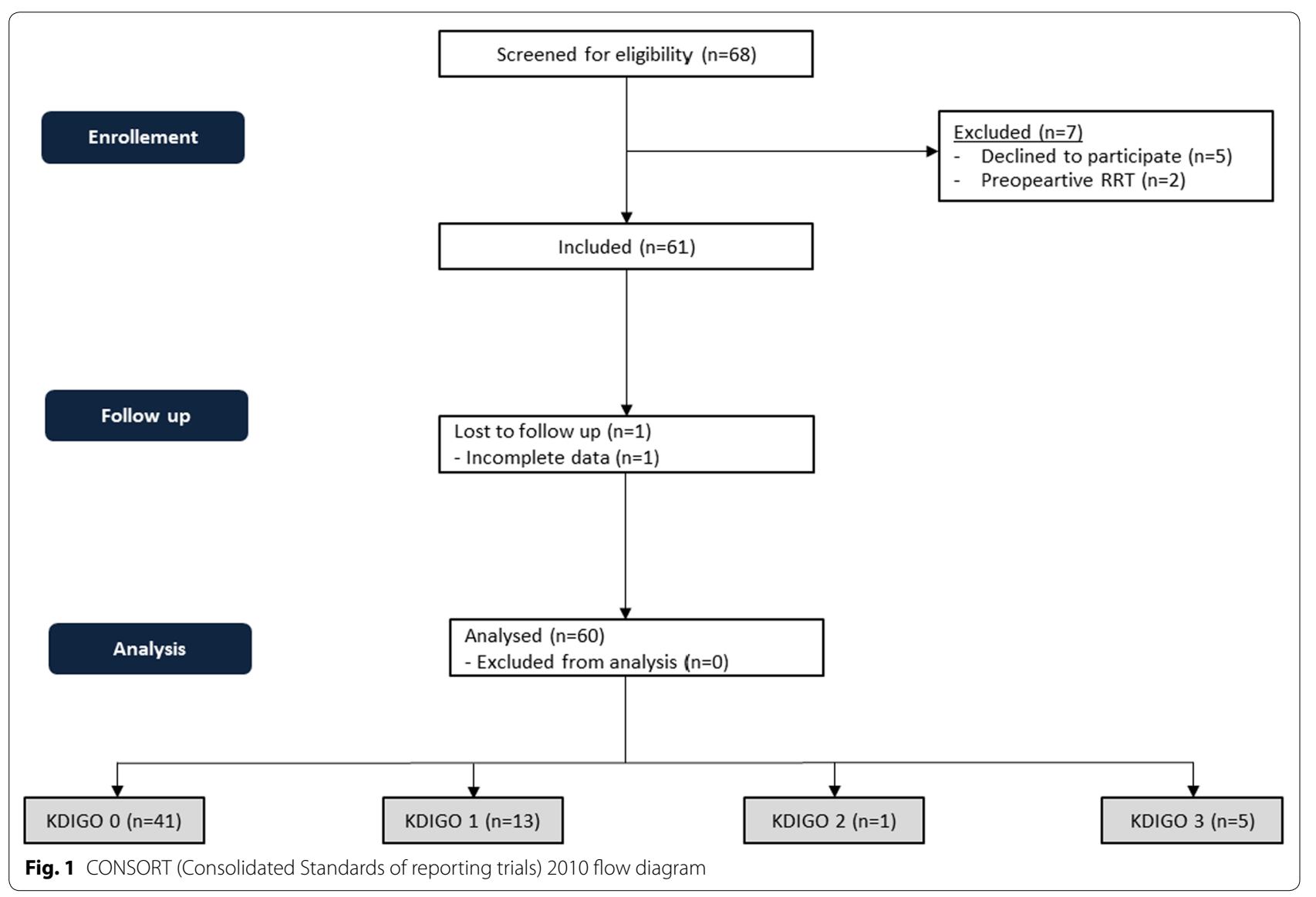


$48 \mathrm{~h}$ after surgery developed in 19 patients (31.7\%): AKI was classified as stage 1 according to KDIGO in 13 patients $(21.7 \%)$ and as stage 2 in one patient (1.7\%). Five patients $(8.3 \%)$ suffered from AKI stage 3 . All of them required renal replacement therapy (RRT) (8.3\%).

The distributions of applied criteria for AKI staging on the basis of serum creatinine or diuresis are given in Table 1. Nine patients were defined as patients with AKI primarily on the basis of increased serum creatinine concentration, and ten patients first reached the threshold of a low diuresis rate.

Pre-procedural characteristics as well as operative variables and postoperative outcomes of patients suffering from AKI 2/3 compared to those without significant postoperative renal dysfunction (KDIGO 2/3) are summarized in Table 2. Patients with renal impairment were significantly older than those without $(76.2 \pm 3.9$ vs. $68.8 \pm 9.1, p=0.003$ ). Preoperative renal function assessed by serum creatinine and eGFR showed no difference between the two groups. Other demographics and prevalence of relevant comorbidities were comparable between both groups. Patients with a moderate-severe AKI suffered from a complicated and prolonged postoperative course: compromised hemodynamics corresponding to shock was observed in five patients with AKI $2 / 3(83.3 \%)$ and only in six (11.1\%) patients with AKI 0/1 $(p<0.001)$. In addition, incidence of sepsis was higher in patients with moderate to severe AKI [5 (83.3 \%) vs. $3(5.6 \%), p<0.001]$. Consecutively, among the AKI $2 / 3$ group ICU stay tended to be longer without reaching statistical significance (ICU stay: 9.7 days \pm 6.4 vs. $5.5 \pm 7.6$, $p=$ n.s.). Hospital mortality was significantly higher in patients with AKI $2 / 3$ [3 (50.0\% vs. 0 (0\%), $p<0.001$ ]. Among the three survivors with AKI2/3, renal function recovered within 6 months after surgery without need for long-term RRT.

\section{Postoperative course of biomarkers}

The postoperative course of serum creatinine, eGFR and urinary [TIMP-2]"[IGFBP7] for patients with AKI stage 2/3

Table 1 Classification criteria for staging of AKI

\begin{tabular}{|c|c|c|c|}
\hline \multirow[t]{2}{*}{ AKI KDIGO stage } & \multirow[t]{2}{*}{ Number } & \multicolumn{2}{|c|}{ Classification criterion for AKI stage } \\
\hline & & $\begin{array}{l}\text { Increase } \\
\text { of serum } \\
\text { creatinine }\end{array}$ & $\begin{array}{l}\text { Decrease of } \\
\text { diuresis or RRT }\end{array}$ \\
\hline 1 & $13(21.7 \%)$ & 8 & 5 \\
\hline 2 & $1(1.7 \%)$ & 1 & 0 \\
\hline 3 & $5(8.3 \%)$ & 0 & 5 \\
\hline All $(1-3)$ & $19(31.7 \%)$ & 9 & 10 \\
\hline
\end{tabular}

Table 2 Patient characteristics of patients with AKI KDIGO $\geq 2$ compared to patients with no or mild AKI (KDIGO 0-1)

\begin{tabular}{|c|c|c|c|}
\hline & $\begin{array}{l}\text { AKI 2/3 } \\
(n=6)\end{array}$ & $\begin{array}{l}\text { AKI 0/1 } \\
(n=54)\end{array}$ & $p$ value \\
\hline Age (years) & $76.2 \pm 3.9$ & $68.8 \pm 9.1$ & 0.003 \\
\hline Male gender $(n, \%)$ & $5(83.3)$ & $43(79.6)$ & n.s. \\
\hline Weight (kg) & $77.8 \pm 11.1$ & $83.7 \pm 17.7$ & n.s. \\
\hline Height (cm) & $174.3 \pm 9.2$ & $171.8 \pm 8.3$ & n.s. \\
\hline CPB time (min) & $113.3 \pm 41.8$ & $102.1 \pm 47.3$ & n.s. \\
\hline $\begin{array}{l}\text { Preoperative Creatinine } \\
(\mathrm{mg} / \mathrm{dl})\end{array}$ & $1.01 \pm 0.17$ & $1.14 \pm 0.23$ & n.s. \\
\hline $\begin{array}{l}\text { Preoperative eGFR } \\
\left(\mathrm{ml} / \mathrm{min} / 1.73 \mathrm{~m}^{2}\right)\end{array}$ & $73.5 \pm 13.9$ & $65.0 \pm 17.5$ & n.s. \\
\hline SAPS & $30.8 \pm 11.6$ & $24.9 \pm 13.8$ & n.s. \\
\hline $\begin{array}{l}\text { Diuresis on the day of CABG } \\
(\mathrm{ml} / \mathrm{kgBW} / \mathrm{h})\end{array}$ & $1.30 \pm 0.33$ & $0.92 \pm 0.69$ & n.s. \\
\hline $\begin{array}{l}\text { Diuresis on POD } 1 \\
(\mathrm{ml} / \mathrm{kgBW} / \mathrm{h})\end{array}$ & $1.69 \pm 0.66$ & $1.27 \pm 0.49$ & n.s. \\
\hline $\begin{array}{l}\text { Fluid balance on the day } \\
\text { of surgery (ml) }\end{array}$ & $2843.0 \pm 973.8$ & $2354.2 \pm 867.5$ & n.s. \\
\hline TISS-28 & $26.0 \pm 6.2$ & $19.7 \pm 10.4$ & n.s. \\
\hline \multicolumn{4}{|l|}{ Comorbidities $(n, \%)$} \\
\hline MI within 6 months & $3(50.0)$ & $13(24.1)$ & n.s. \\
\hline Heart failure NYHA $\geq 3$ & $1(16.7)$ & $3(5.6)$ & n.s. \\
\hline Hypertension & $4(66.7)$ & $49(90.7)$ & n.s. \\
\hline Smoking & $3(50.0)$ & $21(38.9)$ & n.s. \\
\hline Diabetes & $2(33.3)$ & $19(35.2)$ & n.s. \\
\hline COPD & $1(16.7)$ & $7(12.9)$ & n.s. \\
\hline Atrial fibrillation & $4(66.7)$ & $21(38.9)$ & n.s. \\
\hline Peripheral artery disease & $1(16.7)$ & $17(31.5)$ & n.s. \\
\hline $\operatorname{Shock}(n, \%)$ & $5(83.3)$ & $6(11.1)$ & $<0.001$ \\
\hline Sepsis $(n, \%)$ & $5(83.3)$ & $3(5.6)$ & $<0.001$ \\
\hline ICU stay (days) & $9.7 \pm 6.4$ & $5.5 \pm 7.6$ & n.s. \\
\hline Hospital mortality $(n, \%)$ & $3(50.0)$ & $0(0)$ & $<0.001$ \\
\hline
\end{tabular}

COPD chronic obstructive pulmonary disease, SAPS Simplified Acute Physiology Score, TISS-28 Therapeutic Intervention Scoring System 28, POD postoperative day

and those with no or mild AKI is illustrated in Fig. 2. No significant rise in urinary [TIMP-2]"[IGFBP7] was observed in patients with AKI $0 / 1$ at any time indicating that surgical myocardial revascularization per se has no influence on the investigated $\mathrm{G} 1$ cell cycle arrest biomarkers.

In patients developing AKI 2/3 within the 48 postoperative hours, [TIMP-2]*[IGFBP7] increased significantly already $4 \mathrm{~h}$ after surgery compared to patients with AKI $0 / 1$. Notably, a maximum on the 3rd day with an increase to $57.4 \pm 32.8(\mathrm{ng} / \mathrm{ml})^{2} / 1000$ could be observed.

In patients with AKI 0/1, serum creatinine as well as eGR remained stable at all times with no significant undulations over time. In contrast, in patients with AKI 2/3, elevated serum creatinine levels could be observed from postoperative day (POD) 2 to POD 4 with a maximum of $2.6 \pm 1.1 \mathrm{mg} / \mathrm{dl}$ as well as elevated eGFR on POD 3 and 4 . 


\section{a [TIMP 2] [IGFBP7]}

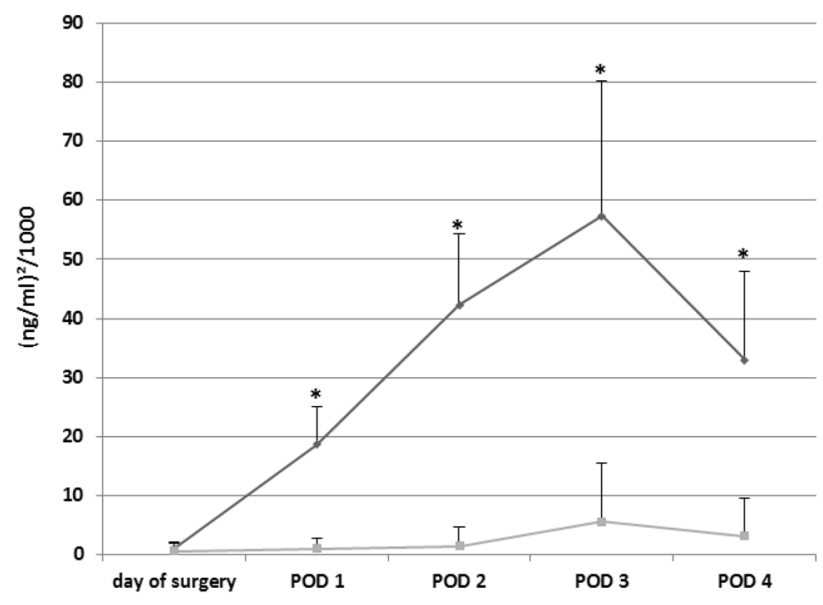

\section{c eGFR}

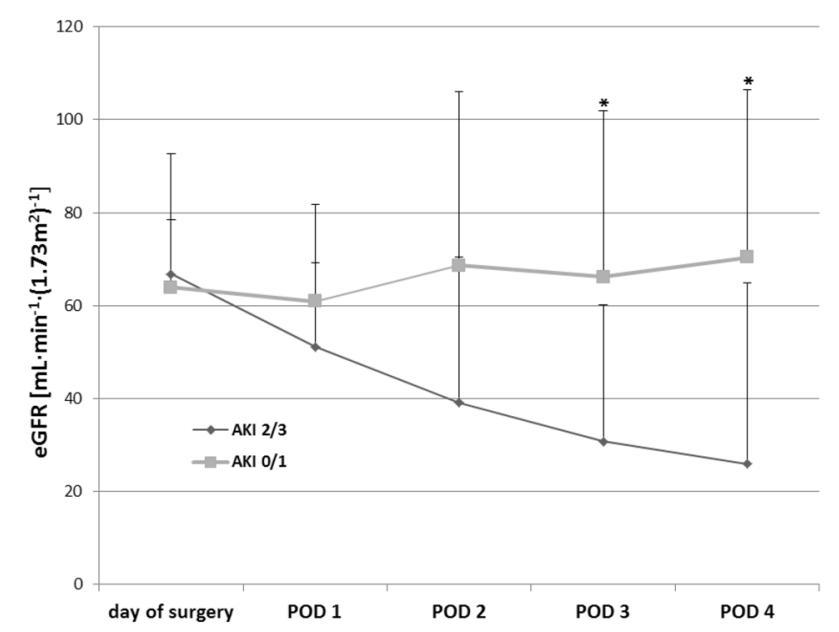

b serum creatinine

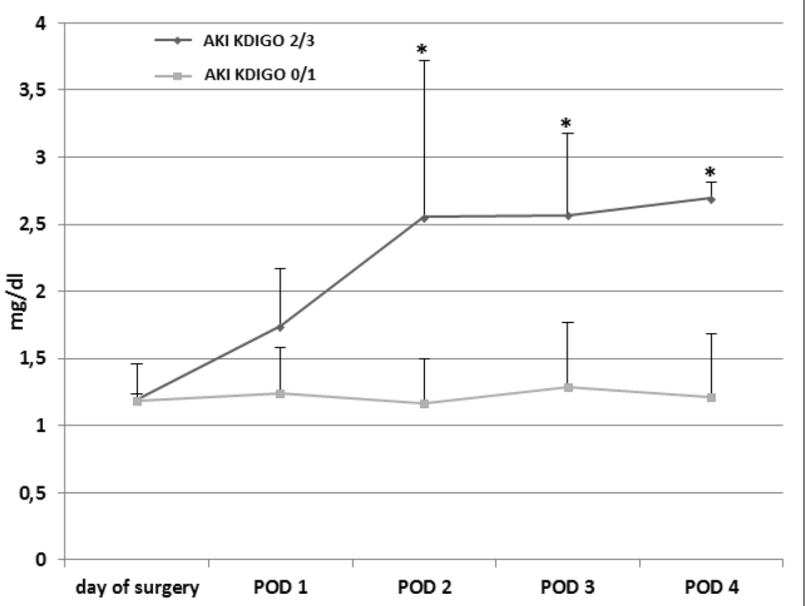

$*=p<0.05$ between patients with $A K I \geq 2$ compared to patients with $A K I \leq 1$

Fig. 2 Postoperative course of [TIMP-2]*[IGFBP7] (a) serum creatinine $(\mathbf{b})$ and (c) eGFR in patients with AKI $\geq 2$ compared to patients with AKI $\leq 1$

Distribution of biomarkers measured on POD 1 after surgery according to the KDIGO classification is shown in Fig. 3. Urinary [TIMP-2]"[IGFBP7] values in patients with AKI 3 (median 0.92, range 0.13-5.93) were significantly higher than in patients with AKI 0 (median 0.065, range 2.69) or AKI 1 (median 0.23, range 0.02-0.53). Accordingly, patients with AKI 2 or 3 showed significantly higher values for [TIMP-2]*[IGFBP7] than patients with AKI $0-1$ (median 1.29, range $0.13-5.93$ vs. 0.10 , range $0.02-2.69, p<0.05$ ).

In contrast, serum creatinine as well as eGFR levels did not differ significantly between subgroups stratified by KDIGO.

\section{Prediction of AKI with biomarkers}

Using ROC analyses, preoperative serum creatinine (AUC 0.329, $95 \%$ CI 0.131-0.527, SE 0.101, $p=0.127$ ), preoperative eGFR (AUC 0.654, $95 \%$ CI 0.446-0.862, SE $0.106, p=0.219$ ), as well as serum creatinine measured $4 \mathrm{~h}$ after surgery (AUC $0.362,95 \%$ CI $0.165-0.559$, SE $0.100, p=0.274$ ) did show low predictive values for AKI stage $2 / 3$ (see Fig. 4 ).

eGFR $4 \mathrm{~h}$ after CABG showed moderate predictive capacity (AUC 0.616, $95 \%$ CI 0.463-0.768, SE 0.78, $p=0.359$ ). In contrast, diagnostic accuracy for urinary [TIMP-2]*[IGFBP7] $4 \mathrm{~h}$ after CABG was more reliable with an AUC 0.861 (95 \% CI 0.717-1.0, SE 0.073, 

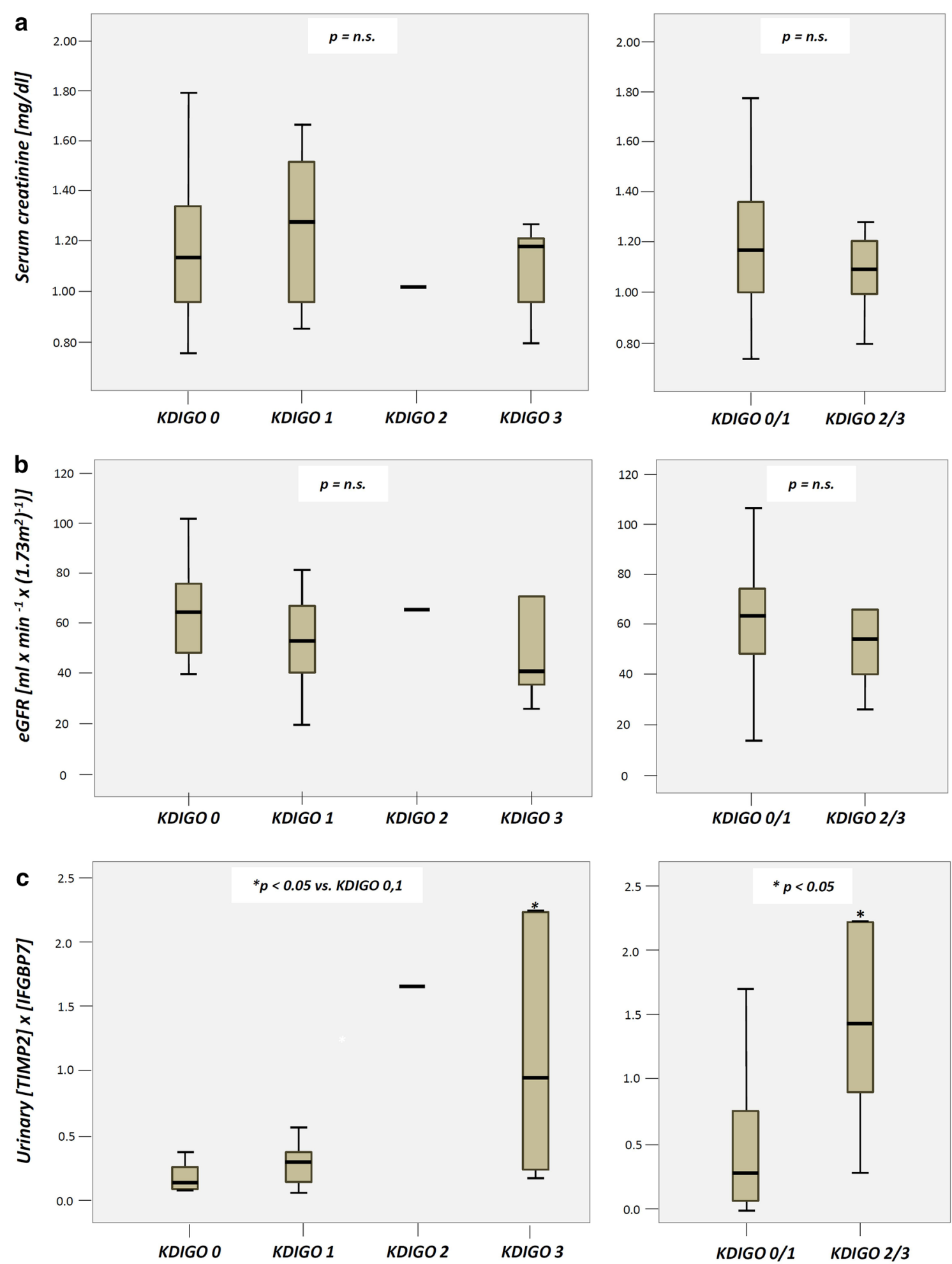

Fig. 3 Boxplots of biomarker values on postoperative day 1 after CABG grouped by KDIGO stage. a Serum creatinine, b eGFR, $\mathbf{c}$ urinary [TIMP 2]*[IGFBP7] 

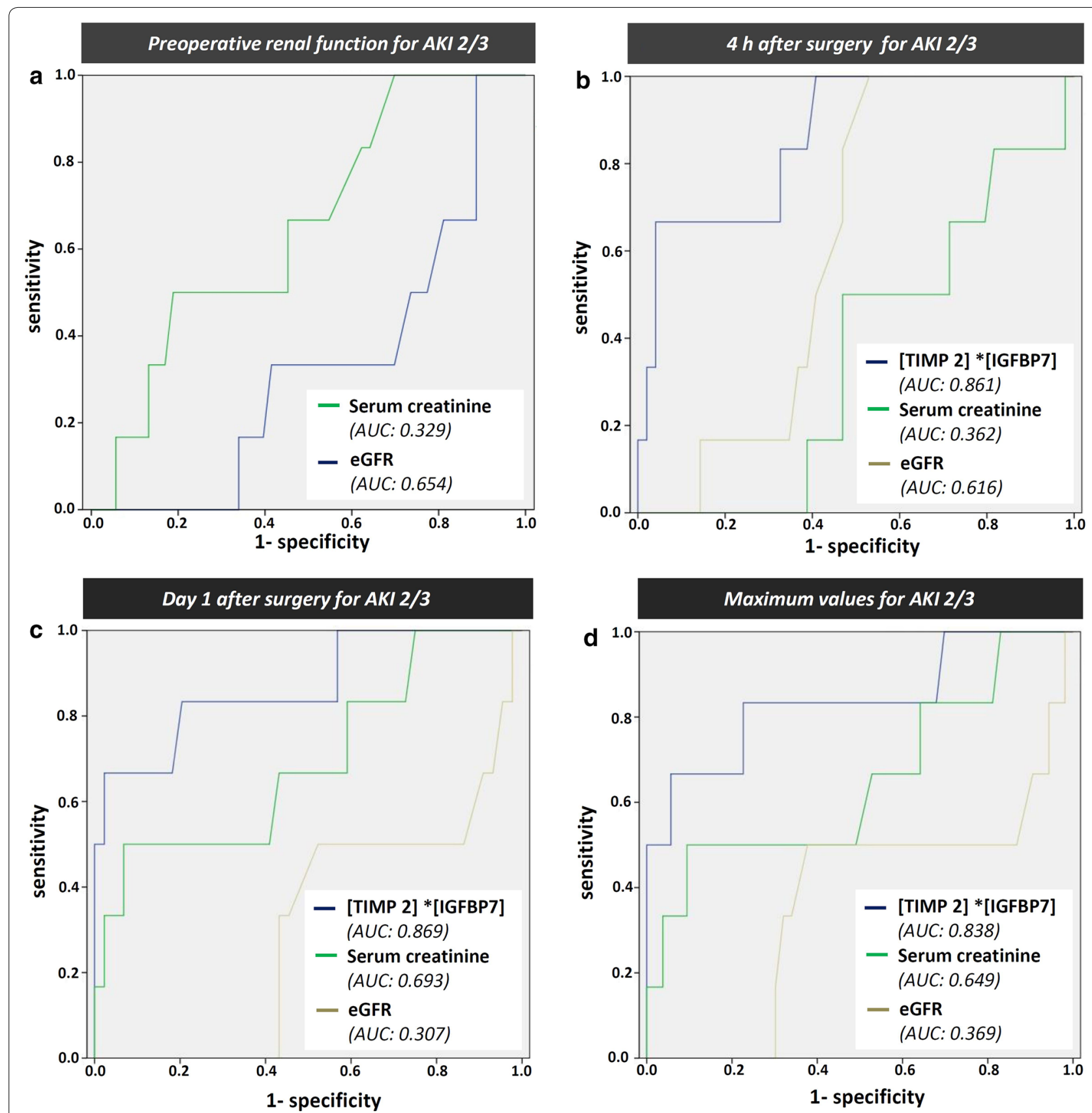

Fig. 4 Receiver operator characteristic (ROC) curve for the prediction of AKI 2-3. a Preoperative serum creatinine and eGFR, b urinary [TIMP2]*[IGFBP7], eGFR and serum creatinine $4 \mathrm{~h}$ after CABG. c urinary [TIMP-2]*[IGFBP7], eGFR and serum creatinine on postoperative day 1 after CABG. d Maximum urinary [TIMP-2]*[IGFBP7], eGFR and serum creatinine during the first $24 \mathrm{~h}$ after CABG

$p=0.04)$, a sensitivity of 0.83 and a specificity of 0.67 when using a cut-off value of 0.15 (Fig. 4).

On the 1st postoperative day, setting a cut-off value of $1.16 \mathrm{mg} / \mathrm{dl}$ for serum creatinine revealed a sensitivity and specificity of 0.67 and 0.57 , respectively (AUC 0.693 , $95 \%$ CI $0.448-0.939$, SE 0.088, $p=0.128)$. eGFR on POD
1 showed inferior predictive properties with an AUC of 0.307 (95\%CI 0.091-0.523, SE 0.110, $p=0.128$ ).

In contrast, [TIMP-2]*[IGFBP7] on postoperative day 1 showed a higher sensitivity and specificity $(0.80$ and 0.81 , respectively), using a cut-off value of 0.89 (AUC 0.869, $95 \%$ CI 0.696-1.0 SE 0.099, $p=0.04$ ). Urinary [TIMP 
2]"[IGFBP7] maximum values within $24 \mathrm{~h}$ after surgery were associated with a comparable sensitivity $(0.83)$ and specificity (0.78) (AUC 0.838, $95 \%$ CI 0.632-1.0, SE $0.105, p=0.007$, cut-off 0.89 ) with maximum serum creatinine and lowest eGFR being associated with a lower sensitivity and specificity. Table 3 summarizes the predictive values of postoperative [TIMP 2]"[IGFBP7] concentrations at three cut-offs: In addition to the optimal cut-off level from our ROC analyses defined by the largest sum of sensitivity and specificity, we applied previously published cut-off points from the Sapphire study: one cut-off with the highest sensitivity $\left.\left[0.3(\mathrm{ng} / \mathrm{ml})^{2} / 1000\right)\right]$ and one with the highest specificity $\left[2.0(\mathrm{ng} / \mathrm{ml})^{2} / 1000\right]$.

\section{Discussion}

In critically ill patients, cardiac surgery with the use of $\mathrm{CPB}$ is the second most common cause of AKI after sepsis, with approximately $1-5 \%$ of patients requiring RRT [16]. AKI in the cardiothoracic population is associated with a significant increase of morbidity and mortality, as well as prolonged length of ICU and hospital stay [1].

In the absence of other appropriate alternatives, the use of serum creatinine as standard diagnostic test for acute kidney injury is commonly accepted among intensivists, despite its known major limitation: Renal function must be impaired more than $50 \%$ before an elevation in serum creatinine can be detected [17]. In addition, serum creatinine does not accurately depict kidney function and rapidly changing glomerular fraction rate (GFR) until a steady state has been reached [17]. Among other shortcomings, serum creatinine levels do not only dependent

Table 3 Analysis of applying best and previously published cut-off points of urinary [TIMP-2]*[IGFBP7] for the prediction of AKI KDIGO 2/3

\begin{tabular}{|c|c|c|c|}
\hline AUC & Cut-off & Sensitivity & Specificity \\
\hline \multicolumn{4}{|c|}{$4 \mathrm{~h}$ after surgery } \\
\hline \multirow[t]{3}{*}{0.861} & 0.15 & 0.83 & 66.7 \\
\hline & 0.3 & 0.67 & 0.76 \\
\hline & 2.0 & 0.33 & 0.98 \\
\hline \multicolumn{4}{|c|}{ Day 1 after surgery } \\
\hline \multirow[t]{3}{*}{0.817} & 0.89 & 0.8 & 0.81 \\
\hline & 0.3 & 1.0 & 0.07 \\
\hline & 2.0 & 0.4 & 0.95 \\
\hline \multicolumn{4}{|c|}{ Maximum early value $e^{a}$} \\
\hline \multirow[t]{3}{*}{0.838} & 0.89 & 0.83 & 0.78 \\
\hline & 0.3 & 0.83 & 0.35 \\
\hline & 2.0 & 66.7 & 0.94 \\
\hline
\end{tabular}

$A K I$ acute kidney injury, $A U C$ area under the curve, IGFBP7 insulin-like growth factor-binding protein 7, KDIGO Kidney Disease: Improving Global Outcomes, $R R T$ renal replacement therapy, TIMP-2 tissue metalloproteinase-2

${ }^{a}$ Defined as maximum level in the first $24 \mathrm{~h}$ after surgery on excretion through glomerular filtration, but also on production mainly by muscle cells and secretion via tubular cells. Because of this, conditions that affect muscle mass and tubular secretion (such as age, gender, race, and level of GFR) may influence the baseline level and the degree of rise in serum creatinine [17]. Moreover, other specific conditions of cardiac surgery with extracorporeal circulation, e.g., the CPB induced hemodilution with a decrease in serum creatinine concentration cumber the creatinine-based diagnosis of AKI [18]. Experimental studies indicate that specific preventive or therapeutic strategies might be able to reduce AKI-associated morbidity and mortality without showing comparable positive results in the clinical setting [19]. This discrepancy might at least partly be explained by the inability to identify AKI at a very early stage. Although Cystatin $\mathrm{C}$ and NGAL seem to be reliable in selected patient cohorts and automated assay methods are commercially available, the value of these two promissing biomarkers in the early diagnosis of AKI remains controversial [20-22].

Taken together, there is no biomarker available for early and reliable detection of AKI, in particular after cardiac surgery, with adequate sensitivity and specificity. Recent studies focused on combinations of biomarkers including urinary insulin-like growth factor-binding protein 7 (IGFBP-7) and tissue inhibitor of metalloproteinases-2 (TIMP-2). This takes into account different pathophysiological mechanisms and, thus, different time courses of biomarker release.

IGFBP7 and TIMP-2 are inducers of the G1 cell cycle arrest found in renal tubular cells being considered as a key mechanism of AKI. They have recently emerged as potential novel markers for risk stratification and early identification of kidney stress. In the multicenter observational Discovery study, a total of 300 potential biomarkers for the detection of AKI were evaluated in a heterogeneous group of 522 patients at high risk of AKI [9]. The results for IGFBP7 and TIMP-2 were better than for any other investigated biomarker (including NGAL, KIM-1, and IL-18) with increased sensitivity and specificity when used as combination compared to its single use (AUC of 0.80 vs. 0.76 and 0.79 alone). Whereas neither TIMP-2 nor IGFBP7 was elevated in patients without AKI being unaffected by important co-morbidities such as chronic kidney disease, diabetes, and sepsis, patients with a [TIMP-2]"[IGFBP7] greater than 0.3 had seven times the risk for AKI.

A follow-up trial-the Opal-trial-using identical enrolment criteria replicated the results of the Discovery study confirming TIMP-2 and IGFBP7 to have better performance than existing markers. Sensitivity and specificity of two cut-off values demonstrated the suitability of these cell cycle arrest markers for clinical application [23]. 
However, etiologies and pathophysiology of AKI differ substantially between patient populations and, therefore, the performance of every biomarker in different patient cohorts and clinical settings may vary significantly requiring careful and specific evaluation of the marker in different scenarios. This also applies for G1 cell cycle arrest marker: IGFBP7 is superior to TIMP-2 in surgical patients whereas TIMP-2 is better for prediction of septic AKI, demonstrating that these two biomarkers are involved in slightly different pathways. Therefore, it is not clear whether the excellent results of the Discovery, Sapphire and Opal study can be transferred to patients undergoing CABG. Studies investigating the role of [TIMP-2]"[IGFBP7] in the prediction of AKI and defining cut-off values in cardiovascular patient populations are rare and currently restricted to adult and pediatric open cardiac surgery. Meersch et al. investigated the diagnostic properties of these biomarkers for the detection of AKI in 50 patients undergoing CABG who were considered to be at high risk for impaired perioperative renal function assessed by the Cleveland Foundation Score [11]. Whereas diagnosis of AKI based on serum creatinine was delayed, TIMP-2 and IGFBP7 increased as early as 4 hours after surgery with a significant difference between patients with AKI and those without. The maximum urinary [TIMP-2]*[IGFBP7] value within the first $24 \mathrm{~h}$ following CABG showed excellent diagnostic accuracy with an area under the receiver operating characteristic curve of 0.84 . Sensitivity was 0.92 , and specificity was 0.81 for a cutoff value of 0.50 . In addition, prediction of renal recovery from AKI was possible with urinary [TIMP-2]*[IGFBP7]. Comparable data were published from the same working group in a pediatric cardio surgical cohort (AUC 0.85 , sensitivity 0.83 , specificity 0.77 for cut-off $0.70\left[(\mathrm{ng} / \mathrm{ml})^{2} / 1000\right]$ [24].

The cut-off values defined in our study were slightly different from recently published studies In the Discovery, Sapphire and Opal study, best cut-off values for discrimination of patients with high risk for oncoming AKI was $0.3(\mathrm{ng} / \mathrm{ml})^{2} / 1000$ whereas Meersch set the value of 0.5 $(\mathrm{ng} / \mathrm{ml})^{2} / 1000$ for the adult and $0.70(\mathrm{ng} / \mathrm{ml})^{2} / 1000$ for the pediatric cardiothoracic population. As mentioned above, etiologies and pathophysiology of AKI differ substantially between patient populations and therefore cut-off values from general surgical, septic, or medical patients might not be applicable to cardiothoracic patients.

Even comparing our results with other studies about the utility of urinary [TIMP-2]"[IGFBP7] for diagnosis of AKI after cardiac surgery may be difficult: Incidence of AKI was $52 \%$ in the study from Meersch vs. $31.7 \%$ in our study. In contrast, five patients suffered from AKI 3 in our series compared to one in the cited trial. The incidence of AKI after cardiac surgery depends on the type of surgery varying significantly between isolated coronary artery bypass grafting, valvular surgery and being the highest for combined CABG+ valvular surgery. Merrsch included all types of cardio surgical procedures not giving any detailed information about performed procedures. In contrast, only isolated CABG procedures were included in our study. In addition, type of CBP and myocardial protection strategy might influence incidence as well as time onset of AKI.

If AKI is recognized early, nephroprotective measures can be considered to reduce exposure to renal insults and potentially avoid the development of higher stage AKI. Although the discussion about preventive or therapeutic interventions in critically ill patients with AKI is controversial, there are some strategies that may be beneficial in the ICU setting: Although there are no specific therapies for AKI, the optimization of fluid balance and hemodynamics as well as a medication review with avoidance of nephrotoxic drugs can reduce the incidence and severity of AKI and improve long-term outcomes [7]. This applies in particular for the subgroup of high risk patients that might be identified better with the cell cycle arrest markers. Accordingly, delayed consultation of a nephrologist is associated with higher mortality and increased dialysis dependence rates in critically ill AKI patients at hospital discharge [25]. In addition, earlier commencement of RRT in critically ill patients with incipient AKI may be beneficial with a reduction of mortality, in particular for patients after cardiac surgery $[6,26]$. Preoperative remote ischemic preconditioning significantly reduced the rate of AKI and use of RRT in patients undergoing cardiac surgery in a recently published multicenter randomized trial [27]. Therefore, our standard regime includes a bundle of interventions if [TIMP 2]"[IGFBP7] is higher than the reported cut-off value including consultation of a nephrologist, extensive chart review and stop of all nephrotoxic agents, goal-directed hemodynamic management, delay-if possible-of any exposure to contrast agent, discussion of early RRT and delay of transferring the patient from the ICU to the normal ward. Therefore, urinary [TIMP-2]"[IGFBP7] might help to initiate established preventive and therapeutic interventions and investigate new concepts to prevent AKI.

\section{Conclusion}

Urinary [TIMP-2]*[IGFBP7] may be considered as early predictor of AKI after CABG surgery. It allows the identification of patients at high risk for the development of severe AKI, even with need for RRT, within the postoperative course. Urinary G1 cell cycle arrest biomarkers allow the diagnosis of AKI earlier than creatinine-based definition of AKI. 


\section{Limitations}

There are some limitations to our study. Due to the relatively small sample size, the predicted cut-off values for [TIMP-2]"[IGFBP7] in the urine may be different from that obtained in other populations.

In the present study, the measurements of the biomarkers were conducted using the commercially available test kit, which only displayed the product of [TIMP-2] and [IGFBP7]. Therefore, we cannot draw any conclusions about the diagnostic properties of TIMP-2 and IGFBP7 alone in comparison to their multiplication.

In the current study, urinary creatinine was not measured to estimate the true creatinine clearance for these patients. There are three major errors that can limit the accuracy of the creatinine clearance as an estimate of GFR: errors in urine collection; increases in both creatinine secretion and extrarenal creatinine degradation as the GFR falls. Because of these limitations, we did not collect $24 \mathrm{~h}$ urine to calculate creatinine clearance but used the Cockcroft-Gault formula to estimate GFR.

\begin{abstract}
Abbreviations
AKI: acute kidney injury, AUC:area under the curve; BMI: Body Mass Index; CABG: coronary artery bypass graft; CAD: coronary artery disease; CBP: cardiopulmonary bypass; COPD: chronic obstructive pulmonary disease; eGFR: estimated glomerular filtration rate; IGFBP7: insulin-like growth factor binding protein 7; ICU: intensive care unit; KDIGO: Kidney Disease: Improving Global Outcomes; LCOS: Iow cardiac output syndrome; log ES I: logistic EuroScore I; LOS: length of stay; LVEF: left ventricular ejection fraction; PHT: pulmonary hypertension; ROC: receiver operating characteristic; RRT: renal replacement therapy; SAPS: Simplified Acute Physiology Score; TISS: Therapeutic Intervention Scoring System; TIMP-2: tissue metalloproteinases 2.
\end{abstract}

\section{Authors' contributions}

FD and KP designed and conducted the study, performed data acquisition, performed statistical analyses, analyzed and interpreted the data and wrote the manuscript draft. MED performed data acquisition and helped with writing the manuscript draft. DSDED were involved in data acquisition and helped with writing the manuscript draft. BJ, HJ and DW were involved in designing the study, analyzing and interpreting the data and revising the manuscript. All authors agree to be accountable for all aspects of the work. All authors read and approved the final manuscript.

\section{Acknowledgements}

This study was supported by Astute Medical that provided the ASTUTE Meter 140 and the test kits. Apart from that, the study was fully financed with departmental funds. The company had no influence on the design, conduct or data analysis of the study or on the preparation of the manuscript. Thanks to Mrs. L. Winkler and Mrs. Ü Türk for collecting urine and blood samples, performing the measurements and taking charge of the logistic and technical requirements.

\section{Competing interests}

Fabian Dusse as well as Kevin Pilarczyk received financial support from Astute Medical for travel and accommodation expenses to participate scientific meetings and present the results of our research in field of AKI. FD received third-party-founds from Astute Medical for research expenses.

Received: 27 July 2015 Accepted: 19 October 2015

Published online: 15 December 2015

\section{References}

1. Rosner MH, Okusa MD. Acute kidney injury associated with cardiac surgery. Clin J Am Soc Nephrol. 2006;1 (1):19-32.

2. Machado MN, Nakazone MA, Maia LN. Prognostic value of acute kidney injury after cardiac surgery according to kidney disease: improving global outcomes definition and staging (KDIGO) criteria. PLoS One. 2014;9(5):e98028.

3. Schiffl $\mathrm{H}$, Fischer R. Five-year outcomes of severe acute kidney injury requiring renal replacement therapy. Nephrol Dial Transplant. 2008;23(7):2235-41

4. Schmitt R, Coca S, Kanbay M, Tinetti ME, Cantley LG, Parikh CR. Recovery of kidney function after acute kidney injury in the elderly: a systematic review and meta-analysis. Am J Kidney Dis. 2008;52(2):262-71.

5. Karkouti K, Wijeysundera DN, Yau TM, Callum JL, Cheng DC, Crowther M, Dupuis JY, Fremes SE, Kent B, Laflamme C, Lamy A, Legare JF, Mazer CD, McCluskey SA, Rubens FD, Sawchuk C, Beattie WS. Acute kidney injury after cardiac surgery: focus on modifiable risk factors. Circulation. 2009;119(4):495-502.

6. Karvellas CJ, Farhat MR, Sajjad I, Mogensen SS, Leung AA, Wald R, Bagshaw SM. A comparison of early versus late initiation of renal replacement therapy in critically ill patients with acute kidney injury: a systematic review and meta-analysis. Crit Care. 2011;15(1):R72.

7. Brienza N, Giglio MT, Marucci M, Fiore T. Does perioperative hemodynamic optimization protect renal function in surgical patients? A metaanalytic study. Crit Care Med. 2009;37(6):2079-90.

8. Devarajan P. Update on mechanisms of ischemic acute kidney injury. J Am Soc Nephrol. 2006;17(6):1503-20.

9. Kashani K, Al-Khafaji A, Ardiles T, Artigas A, Bagshaw SM, Bell M, Bihorac A, Birkhahn R, Cely CM, Chawla LS, Davison DL, Feldkamp T, Forni LG, Gong MN, Gunnerson KJ, Haase M, Hackett J, Honore PM, Hoste EA, JoannesBoyau O, Joannidis M, Kim P, Koyner JL, Laskowitz DT, Lissauer ME, Marx G, McCullough PA, Mullaney S, Ostermann M, RimmeléT, Shapiro NI, Shaw AD, Shi J, Sprague AM, Vincent JL, Vinsonneau C, Wagner L, Walker MG, Wilkerson RG, Zacharowski K, Kellum JA. Discovery and validation of cell cycle arrest biomarkers in human acute kidney injury. Crit Care. 2013;17(1):R25.

10. Bihorac A, Chawla LS, Shaw AD, Al-Khafaji A, Davison DL, Demuth GE, Fitzgerald R, Gong MN, Graham DD, Gunnerson K, Heung M, Jortani S, Kleerup E, Koyner JL, Krell K, Letourneau J, Lissauer M, Miner J, Nguyen HB, Ortega LM, SelfWH, Sellman R, Shi J, Straseski J, Szalados JE, Wilber ST, Walker MG, Wilson J, Wunderink R, Zimmerman J, Kellum JA. Validation of cell-cycle arrest biomarkers for acute kidney injury using clinical adjudication. Am J Respir Crit Care Med. 2014;189(8):932-9.

11. Meersch M, Schmidt C, Van Aken H, Martens S, Rossaint J, Singbartl K, Görlich D, Kellum JA, Zarbock A. Urinary TIMP-2 and IGFBP7 as early biomarkers of acute kidney injury and renal recovery following cardiac surgery. PLoS One. 2014;9(3):e93460.

12. Bossuyt PM, Reitsma JB, Bruns DE, Gatsonis CA, Glasziou PP, Irwig LM, Moher D, Rennie D, de Vet HC, Lijmer JG. Standards for Reporting of Diagnostic Accuracy. The STARD statement for reporting studies of diagnostic accuracy: explanation and elaboration. Clin Chem. 2003;49(1):7-18.

13. Thielmann M, Kottenberg E, Kleinbongard P, Wendt D, Gedik N, Pasa S, Price V, Tsagakis K, Neuhäuser M, Peters J, Jakob H, Heusch G. Cardioprotective and prognostic effects of remote ischaemic preconditioning in patients undergoing coronary artery bypass surgery: a single-centre randomised, double-blind, controlled trial. Lancet. 2013;382(9892):597-604.

14. Kidney Disease: Improving Global Outcomes (KDIGO) Acute Kidney Injury Work Group. KDIGO Clinical Practice Guideline for Acute Kidney Injury. Kidney Int 2012. Suppl, 2:1-138.

15. Dellinger RP, Levy MM, Rhodes A, Annane D, Gerlach H, Opal SM, Sevransky JE, Sprung CL, Douglas IS, Jaeschke R, Osborn TM, Nunnally ME, Townsend SR, Reinhart K, Kleinpell RM, Angus DC, Deutschman CS, Machado FR, Rubenfeld GD, Webb S, Beale RJ, Vincent JL, Moreno R. Surviving Sepsis Campaign Guidelines Committee including The Pediatric Subgroup. Surviving Sepsis Campaign: international guidelines for management of severe sepsis and septic shock, 2012. Intensive Care Med. 2013;39(2):165-228.

16. Uchino S, Kellum JA, Bellomo R, Doig GS, Morimatsu H, Morgera S, Schetz M, Tan I, Bouman C, Macedo E, Gibney N, Tolwani A, Ronco C. Beginning and Ending Supportive Therapy for the Kidney (BEST Kidney) Investigators. Acute renal failure in critically ill patients: a multinational, multicenter study. JAMA. 2005;294(7):813-8. 
17. Waikar SS, Betensky RA, Emerson SC, Bonventre JV. Imperfect gold standards for kidney injury biomarker evaluation. J Am Soc Nephrol. 2012;23(1):13-21.

18. Svenmarker S, Häggmark S, Holmgren A, Näslund U. Serum markers are not reliable measures of renal function in conjunction with cardiopulmonary bypass. Interact CardioVasc Thorac Surg. 2011;12(5):713-7.

19. Ronco C, Bellomo R. Prevention of acute renal failure in the critically ill. Nephron Clin Pract. 2003;93(1):C13-20.

20. Zhang $Z, X u X, N i$, Jin N. Serum cystatin $C$ is associated with renal function recovery in critically ill patients undergoing continuous renal replacement therapy. Nephron Clin Pract. 2012;122(3-4):86-92.

21. Nejat M, Pickering JW, Walker RJ, Westhuyzen J, Shaw GM, Frampton $\mathrm{CM}$, Endre ZH. Urinary cystatin $\mathrm{C}$ is diagnostic of acute kidney injury and sepsis, and predicts mortality in the intensive care unit. Crit Care. 2010;14(3):R85

22. Perry TE, Muehlschlegel JD, Liu KY, Fox AA, Collard CD, Shernan SK, Body SC. CABG Genomics Investigators. Plasma neutrophil gelatinase-associated lipocalin and acute postoperative kidney injury in adult cardiac surgical patients. Anesth Analg. 2010;110(6):1541-7.

23. Hoste EA, McCullough PA, Kashani K, Chawla LS, Joannidis M, Shaw AD, Feldkamp T, Uettwiller-Geiger DL, McCarthy P, Shi J, Walker MG, Kellum JA, Sapphire Investigators. Derivation and validation of cutoffs for clinical use of cell cycle arrest biomarkers. Nephrol Dial Transplant. 2014;29(11):2054-61.
24. Meersch M, Schmidt C, Van Aken H, Rossaint J, Görlich D, Stege D, Malec E, Januszewska K, Zarbock A. Validation of cell-cycle arrest biomarkers for acute kidney injury after pediatric cardiac surgery. PLoS One. 2014;9(10):e110865.

25. Ponce D, Zorzenon Cde P, dos Santos NY, Balbi AL. Early nephrology consultation can have an impact on outcome of acute kidney injury patients. Nephrol Dial Transplant. 2011;26(10):3202-6.

26. Liu Y, Davari-Farid S, Arora P, Porhomayon J, Nader ND. Early versus late initiation of renal replacement therapy in critically ill patients with acute kidney injury after cardiac surgery: a systematic review and meta-analysis. J Cardiothorac Vasc Anesth. 2014;28(3):557-63.

27. Zarbock A, Schmidt C, Van Aken H, Wempe C, Martens S, Zahn PK, Wolf B, Goebel U, Schwer Cl, Rosenberger P, Haeberle H, Görlich D, Kellum JA, Meersch M, RenalRIPC Investigators. Effect of remote ischemic preconditioning on kidney injury among high-risk patients undergoing cardiac surgery: a randomized clinical trial. JAMA. 2015;313(21):2133-41.

\section{Submit your manuscript to a SpringerOpen ${ }^{\odot}$ journal and benefit from:}

- Convenient online submission

- Rigorous peer review

- Immediate publication on acceptance

- Open access: articles freely available online

- High visibility within the field

- Retaining the copyright to your article

Submit your next manuscript at $>$ springeropen.com 